\title{
WORKLOAD, FLOW, AND TELEPRESENCE DURING TELEOPERATION*
}

\author{
J. V. Draper \\ Robotics and Process Systems Division \\ Oak Ridge National Laboratory $\dagger$ \\ Post Office Box 2008 \\ Oak Ridge, Tennessee 37831-6304
}

\author{
Linda M. Blair \\ Human Machine Interfaces, Inc. \\ 10804 Sonja Drive \\ Knoxville, TN 37922
}

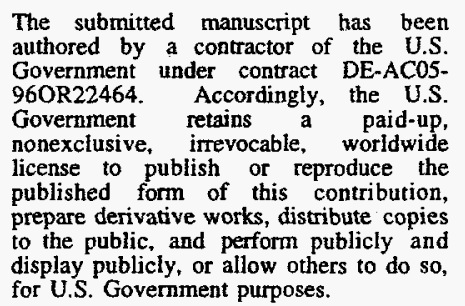

for U.S. Government purposes.

To be presented at the

1996 IEEE International Conference on

Robotics \& Automation

Minneapolis, Minnesota

April 22-28, 1996

\footnotetext{
*Research sponsored by the Office of Environmental Restoration and Waste Management, U.S. Department of Energy, under contract DE-AC05-96OR22464 with Lockheed Martin Energy Research Corp.

$\dagger$ Oak Ridge National Laboratory, managed by Lockheed Martin Energy Research Corp. for the U.S. Department of Energy under contract number DE-AC05-960R22464.

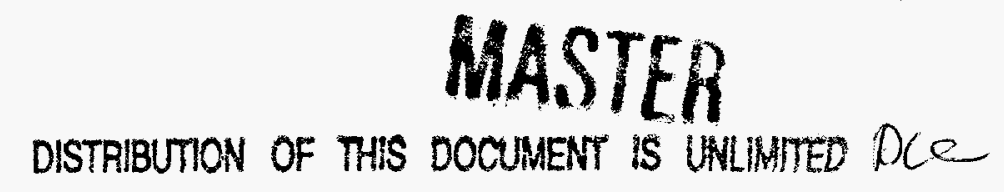




\section{DISCLAIMER}

Portions of this document may be illegible in electronic image products. Images are produced from the best available original document. 


\section{DISCLAIMER}

This report was prepared as an account of work sponsored by an agency of the United States Government. Neither the United States Government nor any agency thereof, nor any of their employees, makes any warranty, express or implied, or assumes any legal liability or responsibility for the accuracy, completeness, or usefulness of any information, apparatus, product, or process disclosed, or represents that its use would not infringe privately owned rights. Reference herein to any specific commercial product, process, or service by trade name, trademark, manufacturer, or otherwise does not necessarily constitute or imply its endorsement, recommendation, or favoring by the United States Government or any agency thereof. The views and opinions of authors expressed herein do not necessarily state or reflect those of the United States Government or any agency thereof.

This report has been reproduced directly from the best available copy.

Available to DOE and DOE contractors from the Office of Scientific and Technical Information, 175 Oak Ridge Turnpike, Oak Ridge, TN 37831 ; prices available at (615) 576-8401.

Available to the public from the National Technical Information Service, U.S. Department of Commerce, 5285 Port Royal Road, Springfield, VA 22161; phone orders accepted at (703) 487-4650. 


\section{Workload, Flow, and Telepresence During Teleoperation}

\author{
John V. Draper \\ Robotics \& Process Systems Division \\ Oak Ridge National Laboratory \\ Post Office Box 2008 Mail Stop 6304 \\ Oak Ridge, Tennessee 37831-6304 \\ draperjv@ornl.gov
}

\author{
Linda M. Blair \\ Human Machine Interfaces, Inc. \\ 10804 Sonja Drive \\ Knoxville, Tennessee 37922 \\ blair@homer.rpsd.ornl.gov
}

\begin{abstract}
There is much speculation about the relationships among workload, flow, telepresence, and performance during teleoperation, but few data that provide evidence concerning them. This paper presents results of an investigation conducted during completion of a pipe cutting task using a teleoperator at the Oak Ridge National Laboratory. The results show support for the hypothesis that telepresence is related to expenditure of attentional resources, and some support for the hypothesis that telepresence is related to flow. The discussion examines the results from an attentional resources perspective on teleoperation.
\end{abstract}

\section{INTRODUCTION}

A recent review [3] found that the literature about teleoperation contains three uses of the term telepresence: the simple, the cybernetic, and the experiential. In the simple definition, telepresence means 'present at a distant site' and refers to teleoperation generally. In the cybernetic definition, telepresence refers to the fidelity of feedback and feed-forward; it is an index of the quality of the human-machine interface. The experiential definition refers to a mental state entered when teleoperator feedback and feed-forward have sufficient scope and fidelity to convince a user that he is physically present at the remote site.

The latter, experiential definition of telepresence is the subject of some debate. The controversy has two sources. The first is the hypothesis that telepresence exists as an experience independent from a previously known phenomenon observed in more mundane settings (flow). The second is the frequent contention that the experience has a positive effect on performance not strictly caused by the quality of the human-machine interface. It is widely accepted in the telerobotics community that experiential telepresence is beneficial. However, as Sheridan commented, "It has yet to be shown how important is the sense of [telepresence] per se as compared to simply having...good sensory feedback." [8]
Flow is a state in which attentional resources are so concentrated on some task as to render one unconscious of stimuli outside of the task, including even awareness of self and the passage of time [2]. Flow and telepresence are alike in that the most singular characteristic of each is concentration on a task. In both, the concentration excludes distracting stimuli to the point of loss of awareness of self as separate from the task. This similarity leads one to speculate whether telepresence is a distinct phenomenon or merely flow during teleoperation.

Fortunately for the sake of hypothesis testing, one critical difference between flow and telepresence may be inferred. Flow may be considered the result of allocation of attentional resources to the point of saturation. Subjective workload reflects the relative allocation of attentional resources: as resource allocation increases, workload is perceived to be greater. Therefore, it may be hypothesized that subjective workload increases with flow. Conversely, experiential telepresence is hypothesized to make tasks easier to perform. Experiential telepresence should reduce the attentional resources necessary to perform a task and, therefore, be inversely related to subjective workload. This leads to a seemingly paradoxical conclusion: experiences of flow and experiential telepresence must be incompatible, if flow results from allocation of attentional resources and experiential telepresence makes tasks easier.

From this, one may conclude that if telepresence is an experience distinct and different from flow, ratings of the experience should be negatively correlated with ratings of effort or workload during teleoperation and positively correlated with measures of task performance. However, if telepresence is flow during teleoperation, ratings of the experience should be positively correlated with measures of effort or workload and may not be correlated with performance. This dual hypothesis provides a framework for a critical experiment concerning the nature and impact of experiential telepresence.

The present paper does not describe such an experiment but presents results of an exploratory nature. It reports data collected in a "naturalistic" setting, that is, observations made without manipulating independent variables. Operators completed a simple task using a teleoperator and task completion time was recorded. Fol- 
lowing each task repetition, the operators completed a multi-scale workload index and a questionnaire containing items pertaining to telepresence and flow. Correlations among these self-reports and the task performance measure were calculated to give insights into the relationships among telepresence, flow, workload, and performance.

\section{METHODS}

\subsection{Teleoperator}

The teleoperator was the Dual Arm Work Module (DAWM) installed in the Robotic Technology Assessment Facility at the Oak Ridge National Laboratory. The DAWM is a dual-arm, hydraulic manipulator controlled by non-replica master controllers. Control is positionposition using Cartesian transformations from master space to slave space. The DAWM provides force reflection to users based on data provided by force/torque sensors located at the wrist of each manipulator arm.

Operators observed the remote site by closed circuit television cameras mounted on the DAWM. There were two cameras just above the arms, one on each side of the DAWM. There was a third camera mounted between the arms. Operators were free to use any camera view available during the task but were not allowed to move the cameras during the task.

\subsection{Task}

The operators used the DAWM and a hydraulic cutter to cut six sections of $2.5 \mathrm{~cm}$ stainless steel tubing mounted on a mock-up rack. The tube sections were approximately 1 meter long, and operators cut a section approximately $75 \mathrm{~cm}$ long from each pipe.

\subsection{Participants}

Three highly trained and experienced teleoperator users participated in the experiment. All were males between the ages of 35 and 45, right-handed, with normal vision. Each operator completed 6 repetitions of the task but only the last 5 were used in the analysis (the first repetition for each participant was discarded as a practice trial).

\subsection{Procedures}

Operators were briefed about the data collection program before it started but they were not informed of the purposes of the experiment until after data collection was completed. In each testing session, an operator com- pleted a single repetition of the task, then the workload questionnaire, and then the flow/telepresence questionnaire. Operators were not permitted to know their times for completing the task, nor were they permitted to know the time required by other operators to do the task.

Each task repetition required about 4 minutes. To prevent them from becoming too fatigued to perform well and from responding automatically to questionnaire items, operators did not perform consecutive task repetitions.

\subsection{Variables}

Task Performance. Task performance was measured as the time, in seconds, required to complete the pipe cutting task.

Workload. Workload was measured using the six scales of the NASA/TLX task workload index [4]. Table 1 identifies and briefly defines the six scales. The NASA/TLX was also used to calculate an overall workload index. Definitions for the NASATLX scales were read to each operator before he completed the NASA/TLX questionnaire, and a sheet containing the definitions was always available for reference.

Flow. Flow was measured along dimensions identified as important by [9], [7], and [5], using questionnaire items found in those studies and modified for teleoperation. Table 2 identifies and defines the dimensions of flow. Flow items described perceptions or events that operators might experience during task performance. Operators responded on a five point scale: they rated the events as occurring (1) very rarely, (2) rarely, (3) sometimes, (4) frequently, or (5) very frequently.

Telepresence. Telepresence was measured as a composite of operators' responses to a pair of similar items. Operators rated the items in the same fashion as the flow items. The specific items were:

1. "I felt as though I were actually in the remote environment as I performed the task."

Table 1. NASA TLX dimensions

\begin{tabular}{ll}
\hline Scale Name & Scale Definition \\
\hline Mental & $\begin{array}{c}\text { How much mental and perceptual ac- } \\
\text { tivity was required? }\end{array}$ \\
Physical & How much physical activity was re- \\
& quired? \\
Temporal & How much time pressure did you feel? \\
Performance & How successful do you think you were? \\
Effort & $\begin{array}{c}\text { How hard did you have to work } \\
\text { (mentally and physically)? }\end{array}$ \\
Frustration & $\begin{array}{c}\text { How discouraged versus gratified, an- } \\
\text { noyed versus content did you feel } \\
\end{array}$ \\
\end{tabular}


Table 2. Dimensions of flow

\begin{tabular}{l|l}
\hline Flow Dimension & Flow Definition \\
\hline Goals & $\begin{array}{l}\text { Clarity of task-related goals } \\
\text { Strength of commitment of atten- } \\
\text { tional resources to task } \\
\text { performance } \\
\text { Degree to which the task was a } \\
\text { challenge for the operator } \\
\text { Degree to which the operator felt in } \\
\text { control of the situation during } \\
\text { task performance } \\
\text { Degree to which operator was con- } \\
\text { cerned about other persons' } \\
\text { opinions of his performance. }\end{array}$ \\
\hline
\end{tabular}

2. "The experience involved unity or fusion of self with the remote environment."

\section{RESULTS}

Before calculating Pearson product-moment correlations among variables, the raw scores were normalized by calculating the within-operator $Z$ score for each. This prevented inter-operator differences from spuriously affecting correlations. Table 3 presents the entire correlation matrix for the data.

\subsection{Workload and Telepresence}

Telepresence ratings were significantly correlated with the workload composite $(\mathbf{r}=0.52)$ and with some of the workload dimensions (Temporal, $\mathbf{r}=0.48$; Effort, $\mathbf{r}=$ 0.58 ; and Frustration, $\mathbf{r}=0.67$ ). As these correlations are positive the evidence is that operators' ratings of telepresence tended to be highest when workload was highest and lowest when workload was lowest. To illustrate the trend, Figure 1 shows a scatter plot of the workload composite and the telepresence ratings.

\subsection{Flow and Telepresence}

Telepresence ratings were significantly correlated with Challenge $(\mathbf{r}=-0.53)$ and Others $(\mathbf{r}=0.61)$. Telepresence increased as skill challenge decreased and increased as concern for others' opinions increased.

\subsection{Workload and Flow}

The workload composite was not significantly correlated with any of the flow dimensions. However, the most important flow dimension, Attention, was strongly correlated with Physical $(\mathbf{r}=0.70)$ and Performance $(\mathbf{r}=$ 0.48 ) workload indexes. High ratings of physical and performance workload and attention occurred together.

\subsection{Task Performance}

Neither telepresence nor flow nor workload correlated very highly with task performance.

\section{DISCUSSION}

Any discussion of these results must be prefaced by a caveat: this is a small set of observations of a small group of operators. Future testing will expand the data set in terms of the number of measurements and the number of tasks used. This approach to the problem of telepres-

Table 3. Correlation matrix for the normalized data

\begin{tabular}{|c|c|c|c|c|c|c|c|c|c|c|c|c|c|}
\hline & Time & Ment. & Phys. & Temp. & Perf. & Effort & Frust. & Goals & Atten. & Chall. & Others & Cont. & Telepr. \\
\hline Time (sec) & 1.00 & & & & & & & & & & & & \\
\hline Mental & -0.12 & 1.00 & & & & & & & & & & & \\
\hline Physical & 0.02 & 0.14 & 1.00 & & & & & & & & & & \\
\hline Temporal & -0.12 & 0.29 & 0.10 & 1.00 & & & & & & & & & \\
\hline Performance & 0.36 & -0.06 & $\underline{0.75}$ & 0.08 & 1.00 & & & & & & & & \\
\hline Effort & 0.12 & $\underline{0.52}$ & 0.07 & $\underline{0.50}$ & 0.102 & 1.00 & & & & & & & \\
\hline Frustration & 0.08 & $\underline{0.50}$ & 0.25 & $\underline{0.50}$ & 0.14 & $\underline{0.65}$ & 1.00 & & & & & & \\
\hline Goals & 0.12 & -0.28 & 0.24 & $\underline{-0.57}$ & 0.02 & -0.42 & -0.022 & 1.00 & & & & & \\
\hline Attention & -0.19 & -0.20 & $\underline{0.70}$ & -0.09 & $\underline{0.48}$ & -0.068 & -0.16 & 0.31 & 1.00 & & & & \\
\hline Challenge & 0.06 & -0.32 & -0.01 & -0.27 & 0.05 & -0.08 & -0.70 & 0.04 & 0.30 & 1.00 & & & \\
\hline Others & -0.19 & 0.20 & -0.15 & $\underline{0.66}$ & -0.34 & $\underline{0.52}$ & $\underline{0.48}$ & -0.28 & -0.13 & -0.31 & 1.00 & & \\
\hline Control & -0.10 & -0.48 & 0.19 & -0.28 & 0.30 & -0.62 & -0.26 & 0.42 & $\underline{0.52}$ & -0.16 & -0.35 & 1.00 & \\
\hline Telepresence & 0.22 & $\overline{0.31}$ & -0.09 & $\underline{0.48}$ & 0.04 & $\overline{0.58}$ & $\underline{0.67}$ & -0.13 & $-\overline{-0.05}$ & -0.53 & $\underline{0.61}$ & 0.04 & 1.00 \\
\hline Workload & 0.09 & 0.61 & 0.59 & $\overline{0.64}$ & 0.52 & $\overline{0.73}$ & $\overline{0.78}$ & -0.27 & 0.17 & -0.34 & 0.35 & -0.29 & 0.52 \\
\hline
\end{tabular}

Note: correlations in boldface and underlined are statistically significant at $\alpha \leq 0.05$. 


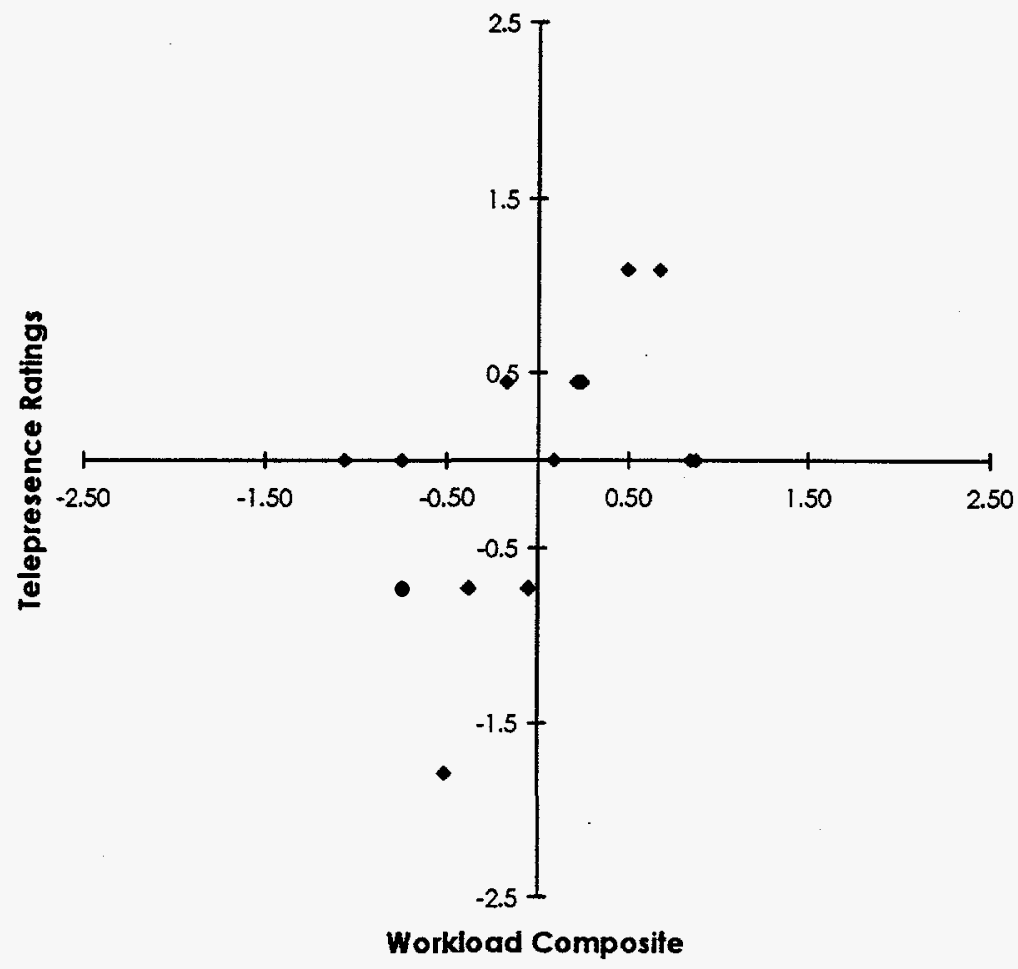

Figure 1. Scatter plot of normalized data for the workload and telepresence ratings

ence seems fruitful, but data reported here must be considered preliminary at this time.

Figure 2 presents a model that may help illustrate the attentional context of experiential telepresence. The model is based on a structured resource perspective, after [6]. Reading from left to right on the figure, information present in the remote environment is available for processing by the human. The human is attending to some remote task, concentrating attentional resources on the completion of the task. Information related to the task is processed by attentive perceptual systems, that is, by perceptual systems devoted to seeking out and interpreting task-related information. This information is centrally processed for developing response strategies that are executed through voice commands, manual control actions, or even self-locomotion. At the same time, information not related to the task, from both the remote area and the local work environment, is also available for processing. This information is perceived by alerting perceptual systems, that is, by perceptual systems not devoted to taskrelated information. These perceptions are mostly ignored (hence the dashed line in Fig. 2). These are distractions. Should they be of sufficient intensity, frequency, or importance they cause an allocation of attentional resources to processing them. Since attentional resources are finite, this causes a concomitant reduction in the attentional resources devoted to the task.

Experiential telepresence may be interpreted as a state arising from commitment of attentional resources to the remote task. The more resources a user devotes to the task, the greater the identification of the user with the task and the stronger the sense of telepresence. However, subjective workload is also a response to the allocation of attentional resources. It seems that the two must be related. One could hypothesize that telepresence (or flow) is the perception arising from allocation of attentional resources, while subjective workload is the perception of the allocation itself.

The hypothesis that experiential telepresence should be inversely related to subjective workload disagrees with this last conclusion, which rests on two assumptions. The first is that experiential telepresence makes tasks easier to perform. The second is that participants' perceptions of their workload will be sensitive to this effect. It has been suggested that telepresence may be increased by improving the fidelity of feedback or of system responses to control inputs, which should have the effect of making information easier to acquire and act on, thereby requiring fewer attentional resources (in other words, by enhancing cybernetic telepresence). It has also been suggested that telepresence can be enhanced by increasing 


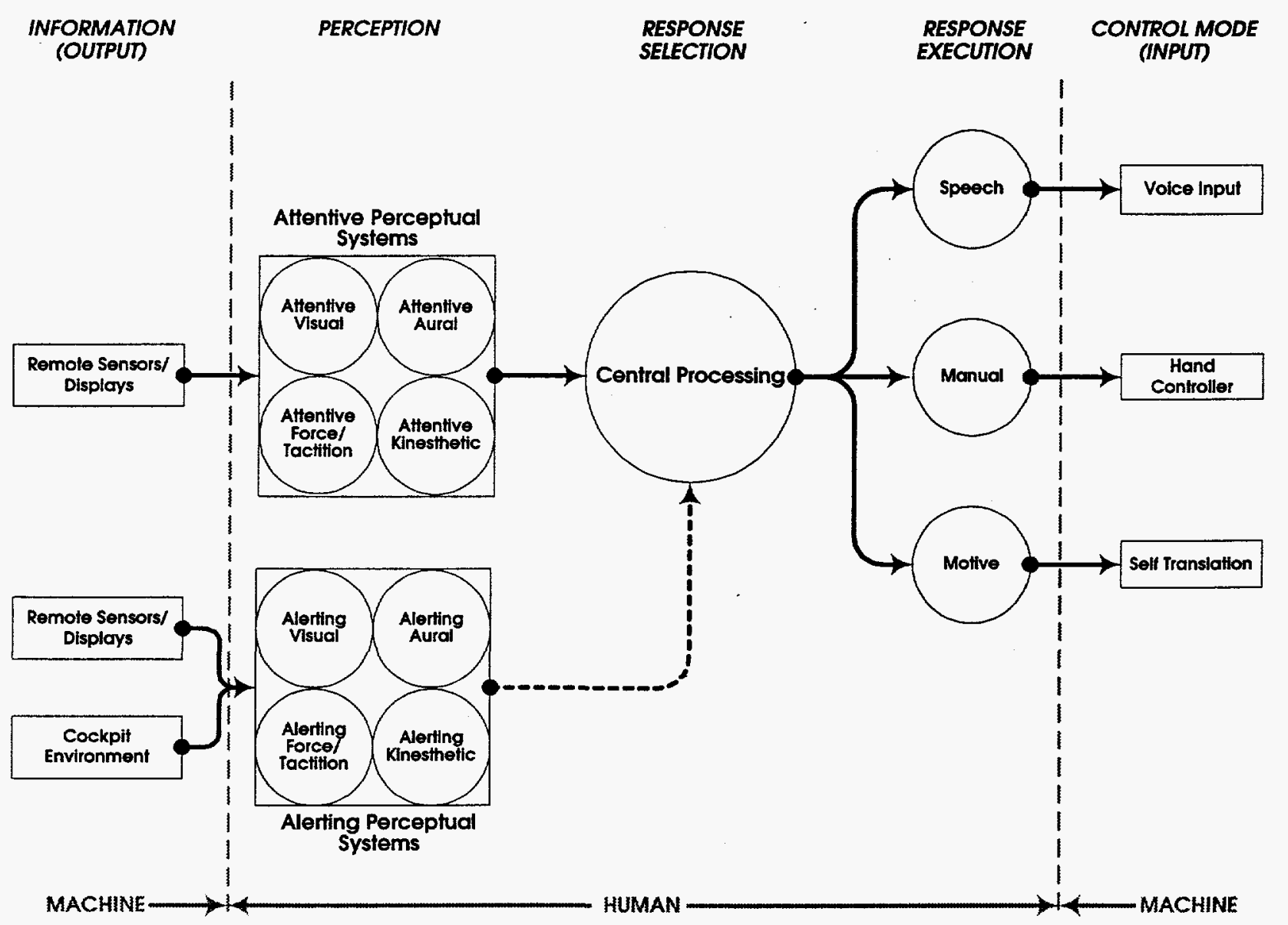

Figure 2. Attentional model for teleoperation

the number of feedback modalities available to operators. This would require the allocation of additional, modalityspecific resources but also should not increase subjective workload given the likely multi-channel structure of attentional resources (see [6]). In either case, the hypothesis that experiential telepresence should reduce subjective workload, if it exists apart from flow, seems valid.

These improvements also enhance cybernetic telepresence, so performance and workload effects could be explained without reference to experiential telepresence. For experiential telepresence to be a useful construct it must be demonstrated that it functions independently of enhancements to cybernetic telepresence. Otherwise, scientific parsimony demands that the simpler explanation be adopted. In this case, experiential telepresence hypothesizes an additional construct without increasing explanatory power and should be rejected. It is also possible that the sense of presence exists apart from flow and is unrelated to workload and task performance. However, if this is the case it seems to be a barren topic for further discussion.
With that background, the results of this study indicate that the sense of experiential telepresence is positively correlated with workload and with operators' ratings of temporal pressures, effort, and frustration. Therefore, it seems that experiential telepresence is directly, not inversely, related to workload. This means that increasing telepresence was associated with increasing task difficulty, which is counter to the relationship hypothesized in the literature about experiential telepresence. Furthermore, there was no significant correlation between telepresence and task performance. These results support the hypothesis that telepresence is related to the expenditure of attentional resources.

However, if telepresence is a form of flow, ratings of telepresence should be positively correlated with the flow dimensions. In fact, the ratings of telepresence and flow were related in a pattern that is difficult to interpret. Three flow dimensions were not significantly correlated with telepresence. Telepresence was negatively correlated with Challenge, indicating that telepresence increased as users felt the task became less challenging. Telepresence was positively correlated with Others, indicating telepres- 
ence increased as concern for others' opinions of performance increased. The significant correlations indicate that telepresence is, in some way, related to flow. The fact that one correlation is positive and the other negative makes the exact nature of the relationship difficult to understand. The relationship between Challenge and telepresence is particularly puzzling given the relationship between telepresence and workload and its components.

In summation, the results indicate that the attentional resources approach to telepresence has merit, and that the experience of telepresence is related to the expenditure of attentional resources. In these data, telepresence and workload were not inversely related, as could be expected from the literature about telepresence, but rather directly related. There was some evidence that telepresence and flow are related, but the nature of the relationship did not appear to be as simple as hypothesized.

The difficulty in assessing the impact of experiential telepresence comes in part from the difficulty of manipulating it without affecting cybernetic telepresence. Certain enhancements to teleoperators increase both cybernetic telepresence and, potentially, experiential telepresence; experimental manipulations made to assess the impact of the latter must hold the former constant or the effects of the two are confounded. Studying experiential telepresence without experimental manipulations as this experiment did avoids that problem. However, the correlational approach followed here makes it difficult to assign causation. The most common causal hypothesis is something like: cybernetic telepresence leads to perceptions of experiential telepresence which leads to performance and workload. An alternative causal chain might be: cybernetic telepresence leads to performance and workload which lead to perceptions of experiential telepresence. Correlational studies like this one can identify associations among variables but cannot always explain causation.

Some readers may question the validity of an approach that depends upon subjective measures of workload and telepresence. However, if telepresence is primarily an experience, self-reports of the strength of the experience are the most direct measures of the phenomenon. Furthermore, subjective measurement of workload has a long and successful history in the study of humanmachine interaction. Indeed, according to [1], subjective measures are more reliable and more sensitive to workload differences than secondary-task or physiological measures, in spite of the seeming objectivity of the latter two types.

This research attempted to advance the discussion of experiential telepresence by presenting some observations of it along with observations of task performance, flow, and workload. This was done in the context of a hypothesis that allows a critical comparison of two competing perspectives on experiential telepresence. The experiment does not provide conclusive answers to the question, but, perhaps, it introduces a means for finding the conclusive answer. Hopefully, future investigations along these lines will be pursued at this laboratory and others.

\section{ACKNOWLEDGMENTS}

This work was performed at the Oak Ridge National Laboratory, managed by Lockheed Martin Energy Research Corp. for the U.S. Department of Energy under contract DE-AC05-84OR21400. The opinions expressed are those of the authors and not necessarily those of the Oak Ridge National Laboratory, Lockheed Martin Energy Research Corp., or the U.S. Department of Energy.

\section{REFERENCES}

[1] J. G. Casali and W. W. Wierwille, "On the measurement of pilot perceptual workload: a comparison of assessment techniques addressing sensitivity and intrusion issues," Ergonomics, vol. 27, pp. 1033-1050, 1984.

[2] M. Csikszentmihalyi, Beyond Boredom and Anxiety. San Francisco, CA: Jossey-Bass Publishers, 1975.

[3] J. V. Draper, "Teleoperators for advanced manufacturing: applications and human factors challenges," International Journal of Human Factors in Manufacturing, vol. 5, pp. 53-85, 1995.

[4] Human Performance Research Group, Task Load Index (NASA-TLX). Moffett Field, CA: NASA Ames Research Center, 1987.

[5] S. A. Jackson, "Elite Athletes in Flow: The Psychology of Optimal Sport Experience," Doctoral Dissertation. Greensboro, NC: University of North Carolina at Green sboro, 1992.

[6] D. Navon and D. Gopher, "On the economy of the human information-processing system," Psychological Review, vol. 86, 1979.

[7] J. L. Progen, "An Exploration of the Flow Experience Among Selected College Athletes," Doctoral Dissertation. Greensboro, NC: University of North Carolina at Greensboro, 1981.

[8] T. B. Sheridan, Telerobotics, Automation, and Human Supervisory Control. Cambridge, MA: The MIT Press, 1992.

[9] N. L. Stevens, "The Investigation of Anxiety, Motivation, and Flow Experience in Competitive Sport," Doctoral Dissertation. College Park, PA: Pennsylvannia State University, 1979. 